\title{
A numerical model for the design of a mixed flow cryogenic turbine
}

\author{
Subrata Kr. Ghosh \\ Department of ME \& MME, Indian School of Mines, Dhanbad, Jharkhand, INDIA \\ E-mail:subratarec@yahoo.co.in
}

\begin{abstract}
Present day cryogenic gas turbines are in more popular as they meet the growing need for low pressure cycles. This calls for improved methods of turbine wheel design. The present study is aimed at the design of the turbine wheel of mixed flow impellers with radial entry and axial discharge. In this paper, a computer code in detail has been developed for designing such turbine wheel. To determine the principal dimensions of the turbine wheel, optimum operating speed has been taken from design charts based on Similarity principles. The algorithm developed, allows any arbitrary combination of fluid properties, inlet conditions and expansion ratio, since the fluid properties are properly taken care of in the relevant equations. The computational process is illustrated with an example. The main dimensions, thermodynamic properties at different states, velocity and angles at entry and exit of the turbine wheel were worked out. The work may help the researchers for further design and development of cryogenic turboexpander depending on their operating parameters.
\end{abstract}

Keywords: Cryogenic, turboexpander, mixed flow turbine, flow angle, flow velocity

\section{Introduction}

Compressor, heat exchanger, expansion turbine, and vacuum vessel are the main components to establish any cryogenic liquid plant. To establish the set up, different companies are indigenously available in India for compressor, heat exchanger and vacuum vessel. But the turboexpander is not readily available in market. As the technology is not yet developed indigenously, we are forced to import the whole liquid plant. A simple method sufficient for the design of a high efficiency expansion turbine is outlined by Kun (1987) and Kun et al. (1985). A study was initiated in 1979 to survey operating plants and generates the cost factors relating to turbine by Kun \& Sentz (1985). They are also sometimes referred to as design parameters, since the shape dictates the type of design to be selected. Corresponding approximately to the optimum efficiency a cryogenic expander may be designed with selected specific speed and specific diameter. Sixsmith et al. (1988) in collaboration with Goddard Space Flight Centre of NASA, developed miniature turbines for Brayton Cycle cryocoolers. Another programme at IIT Kharagpur developed a turboexpander unit by using aerostatic thrust and journal bearings which had a working speed up to 80,000 rpm. The detailed summary of technical features of the cryogenic turboexpander developed in various laboratories has been given in the $\mathrm{PhD}$ dissertation of Ghosh (2002). The detailed design parameters for a $90^{\circ}$ inward radial flow turbine is shown in the PhD dissertation of Ghosh. Bruce (Bruce, 1998) described the aerodynamic and structural analysis for the complete design of turbo-machinery rotor. The major elements of the turboexpander are briefly discussed in the paper published by Ghosh et al. (2005). Baines (2002) has shown that mixed flow turbine concepts can achieve stage loadings that are about $20 \%$ greater than those of a conventional radial turbine, without any increase in blade speed and maintaining structural integrity. Descombes (2003) has high-lighted the variability of the local distribution of velocities and pressures within the rotor and gives a real image of energy transformation for nearly ideal zero incidence conditions at the rotor inlet. Abidat (2006) has taken care in the design of the volute essential component of a radial and mixed flow turbines and interest was focused on the influence of the volute inlet flow conditions on its performance. A method of computing blade profiles has been worked out by Hasselgruber (1958), which has been employed by Kun \& Sentz (1985) and by Balje (1970, 1981). Effect of some of the turbine operating and design parameters on the flow path and its curvature have been analyzed and presented by Ghosh et al. (2009). The computational procedure developed describes the three-dimensional contours of the blades for the turbine wheel. 


\section{Fluid parameters and layout of components}

The fluid specifications have been dictated by the requirements of a small refrigerator producing less than $1 \mathrm{KW}$ of refrigeration. Turbine efficiency of $75 \%$ has been assumed following the experience of the workers (Beasley et al., 1965; Yang et al., 1990; Denton, 1996; Jekat, 1957). The inlet temperature has been specified rather arbitrarily, chosen in such a way that even with ideal (isentropic) expansion; the exit state should not fall in the two-phase region. The basic input parameters for the system are given in Table 1. Figure 1 shows the longitudinal section of a typical cryogenic turboexpander displaying the layout of the components within the system. The major components of the turboexpander are shown in Table 2.

Table 1:Basic input parameters for the cryogenic expansion turbine system

\begin{tabular}{|l|l|l|l|l|l|}
\hline Working fluid & $:$ & Nitrogen & Discharge pressure & $:$ & $1.5 \mathrm{bar}$ \\
\hline Turbine inlet temperature & $:$ & $122 \mathrm{~K}$ & Throughput & $:$ & $67.5 \mathrm{~nm} 3 / \mathrm{hr}$ \\
\hline Turbine inlet pressure & $:$ & $6.0 \mathrm{bar}$ & Expected efficiency & $:$ & $75 \%$ \\
\hline
\end{tabular}

Table 2: Basic unit of a turboexpander assembly

\begin{tabular}{|l|l|l|l|}
\hline Turbine wheel & Nozzle & Diffuser & Shaft \\
\hline Brake compressor & Journal bearings & Thrust bearings & Housing \\
\hline
\end{tabular}

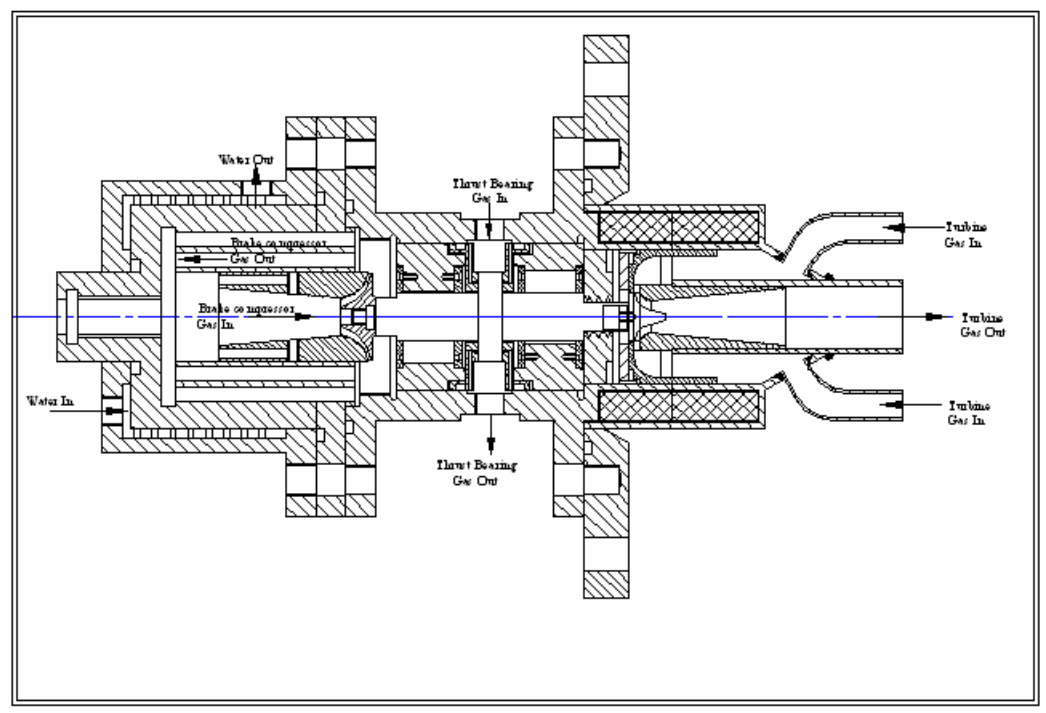

Figure 1: Longitudinal section of the expansion turbine displaying the layout of the components

\section{Design of turbine wheel}

The design of turbine wheel has been done following the method outlined by Balje (1981) and Kun \& Sentz (1985), which are based on the well known "similarity principles". The similarity laws state that for given Reynolds number, Mach number and Specific heat ratio of the working fluid, to achieve optimized geometry for maximum efficiency, two dimensionless parameters: specific speed and specific diameter uniquely determine the major dimensions of the wheel and its inlet and exit velocity triangles. Specific speed $\left(n_{s}\right)$ and specific diameter $\left(d_{s}\right)$ are defined as:

Specific speed

Specific diameter

$$
n_{s}=\frac{\omega \sqrt{Q_{3}}}{\left(\Delta h_{i n-3 s}\right)^{\frac{3}{4}}}
$$$$
d_{s}=\frac{D_{2} \times\left(\Delta h_{i n-3 s}\right)^{\frac{1}{4}}}{\sqrt{Q_{3}}}
$$ 
In the definition of $n_{s}$ and $d_{s}$ the volumetric flow rate $Q_{3}$ is that at the exit of the turbine wheel. Kun and Sentz (1985), however suggest two empirical factors $k_{1}$ and $k_{2}$ for evaluating $Q_{3}$ and $h_{3 s}$, which define $n_{s}$ and $d_{s}$.

$$
\begin{aligned}
& Q_{3}=k_{1} Q_{e x} \text { and } \\
& \rho_{3}=\rho_{e x} / k_{1} \\
& \Delta h_{\text {in-3s }}=k_{2}\left(h_{0 i n}-h_{\text {exs }}\right)
\end{aligned}
$$

The factors $k_{1}$ and $k_{2}$ account for the difference between the states ' 3 ' and 'ex' caused by pressure recovery and consequent rise in temperature and density in the diffuser as shown in Figure 2. Following the suggestion of Kun and Sentz (1985), $k_{2}$ value is 1.03. The factor $k_{1}$ represents the ratio $Q_{3} / Q_{e x}$, which is also equal to $\rho_{\text {ex }} / \rho_{3}$. The value of $Q_{e x}$ and $\rho_{\text {ex }}$ are known at this stage, where as $Q_{3}$ and $\rho_{3}$ are unknown. By taking a guess value of $k_{1}$, the volume flow rate $\left(Q_{3}\right)$ and the density $\left(\rho_{3}\right)$ at the exit condition of the turbine wheel can be calculated from equations (3) and (4) respectively. If the guess value is correct, then $Q_{3}$ and $\rho_{3}$ should give a turbine exit velocity $C_{3}$ that satisfies the velocity triangle as described in equation (13); otherwise the iteration process is repeated with a new guess value of $k_{1}$. The value of $Q_{3}$ determines turbine exit velocity uniquely. The thermodynamic relations for reversible isentropic flow in the diffuser are,

$$
h_{03}=h_{0 e x}, \quad s_{3}=s_{e x} \text { and } \quad h_{3}=h_{03}-\frac{C_{3}^{2}}{2}
$$

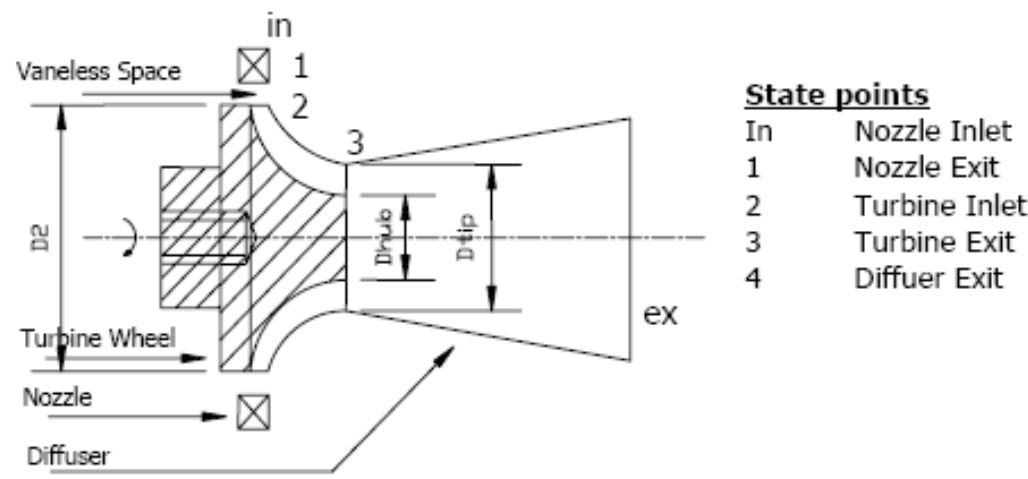

Figure 2: State points of turboexpander

Using the property tables, the value of $\rho_{3}$ can be estimated from $s_{3}$ and $h_{3}$. When the difference between the calculated and initial values of $\rho_{3}$ is within the prescribed limit, the iteration is converges. Since the change in entropy in the diffuser is small compared to the total entropy change, assumption of isentropic flow will lead to very little error. The estimation $k_{1}$ does not deviate appreciably, if the expansion of fluid from 'in' to 'ex' is non-isentropic. With this assumption, the value of $k_{1}$ is estimated to be 1.11, starting with the initial guess value of 1.02. A flow chart for determining the value of $k_{1}$ is described in the Figure 9.

For estimating the thermodynamic properties at different states along the flow passage, the software package ALLPROPS 4.2 available from the University of Idaho, Moscow (Lemmon et al., 1995) is used. Table 3 represents the thermodynamic states at the inlet of the nozzle and the exit of the diffuser according to input specifications. The exit state has two different columns, one is isentropic expansion and other is with isentropic efficiency of $75 \%$.

Using data from Table 3 ,

$$
\begin{aligned}
& Q_{e x}=\frac{\dot{m}_{t r}}{\rho_{e x}}=\frac{23.26 \times 10^{-3}}{5.86}=3.97 \times 10^{-3} \mathrm{~m}^{3} / \mathrm{s} \\
& \rho_{3}=\frac{\rho_{e x}}{k_{1}}=\frac{5.86}{1.11}=5.27 \mathrm{~kg} / \mathrm{m}^{3} \\
& Q_{3}=k_{1} Q_{e x}=4.42 \times 10^{-3} \mathrm{~m}^{3} / \mathrm{s}
\end{aligned}
$$




$$
\Delta h_{\text {in }-3 s}=k_{2}\left(h_{0, \text { in }}-h_{e x, s}\right)=1.03 \times 38.7 \times 10^{3}=39861 \mathrm{~J} / \mathrm{kg}
$$

From Balje (1981) the peak efficiency of a radial inflow turbine corresponds to the values of:

$$
n_{s}=0.54 \text { and } d_{s}=3.4
$$

Substituting these values in equations (1) and (2) respectively, yields

Rotational speed $\omega=22910 \mathrm{rad} / \mathrm{s}=2,18,775 \mathrm{r} / \mathrm{min}$,

Wheel diameter $D_{2}=16.0 \mathrm{~mm}$.

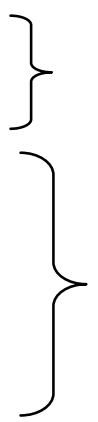

Power produced $\mathrm{P}=\dot{\mathrm{m}}\left(\mathrm{h}_{0 \text { in }}-\mathrm{h}_{\mathrm{ex}}\right)=\dot{\mathrm{m}} \eta\left(\mathrm{h}_{0 \text { in }}-\mathrm{h}_{\mathrm{exs}}\right)=0.9 K W$

Tip speed

$$
U_{2}=\omega D_{2} / 2=183.28 \mathrm{~m} / \mathrm{s}
$$

Spouting velocity

$$
\mathrm{C}_{0}=\sqrt{2 \Delta \mathrm{h}_{\text {in-exs }}}=278.20 \mathrm{~m} / \mathrm{s} \text { and }
$$

Velocity ratio

$$
\frac{U_{2}}{C_{0}}=0.66
$$

According to Whitfield and Baines (1990), the velocity ratio $U_{2} / C_{0}$ in a radial inflow turbine generally remains within 0.66 and 0.70. The ratio of exit tip diameter to inlet diameter should be limited to a maximum value of 0.70 (Dixon, 1978; Rohlik, 1968) to avoid excessive shroud curvature. Corresponding to the peak efficiency point (Kun and Sentz, 1985):

$$
\begin{aligned}
& \xi=\mathrm{D}_{\text {tip }} / \mathrm{D}_{2}=0.676 \\
& D_{\text {tip }}=10.8 \mathrm{~mm}
\end{aligned}
$$

Table 3:Thermodynamic states at inlet and exit of prototype turbine

\begin{tabular}{|l|l|l|l|}
\hline & Inlet & isentropic exit state $(e x, s)$ & Actual exit state $(e x)$ \\
\hline Pressure $($ bar $)$ & 6 & 1.50 & 1.50 \\
\hline Temperature $(\mathrm{K})$ & 122 & 81.72 & 89.93 \\
\hline Density $\left(\mathrm{kg} / \mathrm{m}^{3}\right)$ & 17.78 & 6.55 & 5.86 \\
\hline Enthalpy $(\mathrm{kJ} / \mathrm{kg})$ & 119.14 & 80.44 & 90.11 \\
\hline Entropy $(\mathrm{kJ} / \mathrm{kg} . \mathrm{K})$ & 5.339 & 5.339 & 5.452 \\
\hline
\end{tabular}

Balje (1981) prescribes values for the hub ratio $\lambda=D_{h u b} / D_{\text {tip }}$ against $n_{s}$ and $d_{s}$ for axial flow turbines, but makes no specific recommendation for radial flow machines. In axial flow and large radial flow turbines, a small hub ratio would lead to large blade height, with associated machining difficulties and vibration problems. But in a small radial flow machine, a lower hub ratio can be adopted without any serious difficulty and with the benefit of a larger cross section and lower fluid velocity. According to Rohlik (1968), the exit hub to tip diameter ratio should maintained above a value of 0.4 to avoid excessive hub blade blockage and energy loss. Kun and Sentz (1985) have taken a hub ratio of 0.35 citing mechanical considerations.

$$
\begin{aligned}
& \lambda=D_{\text {hub }} / D_{\text {tip }}=.425 \\
& D_{\text {hub }}=4.6 \mathrm{~mm}
\end{aligned}
$$

There are different approaches for choosing the number of blades, the most common method is based on the concept of 'slip', as applied to centrifugal compressors (Rohlik, 1968; Stewart and Glassman, 1973; Jadeja et al., 1985). Denton (1996) has given same guidance on the choice of number of blades by ensuring that the flow is not stagnant on the pressure surface. For small turbines, the hub circumference at exit and diameter of milling cutters available determine the number of blades. In this design the number of blades $\left(Z_{t r}\right)$ are chosen to be 10 , and the thickness of the blades to be $0.6 \mathrm{~mm}$ throughout.

From geometrical considerations:

$$
A_{3}=\frac{\pi}{4}\left(D_{t i p}{ }^{2}-D_{h u b}{ }^{2}\right)-\frac{Z_{t r} t_{t r}\left(D_{t i p}-D_{h u b}\right)}{2 \sin \beta_{\text {mean }}}
$$




$$
\begin{aligned}
& Q_{3}=A_{3} C_{3}=C_{3}\left[\frac{\pi}{4}\left(D_{t i p}{ }^{2}-D_{h u b}{ }^{2}\right)-\frac{Z_{t r} t_{t r}\left(D_{t i p}-D_{h u b}\right)}{2 \sin \beta_{\text {mean }}}\right] \\
& Q_{3}=C_{3} \frac{\pi}{4}\left(D_{t i p}{ }^{2}-D_{h u b}{ }^{2}\right)-\frac{Z_{t r} t_{t r}\left(D_{t i p}-D_{h u b}\right)}{2} \times W_{3}
\end{aligned}
$$

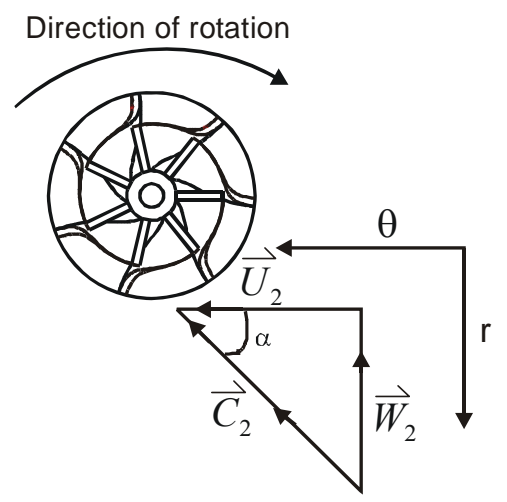

(a) Inlet velocity triangle in the $\mathrm{r}-\theta$ plane

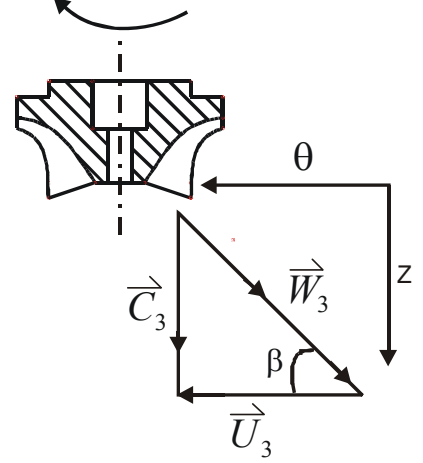

Figure 3: Inlet and exit velocity triangles of the turbine wheel

From the velocity triangle in Figure 3

$$
\tan \beta_{\text {mean }}=\frac{C_{3}}{U_{3, \text { mean }}}=\frac{4 C_{3}}{\omega\left(D_{\text {tip }}+D_{\text {hub }}\right)}
$$

For a given value of $Q_{3}$ as given by equation (6), equations (13) and (14) are solved simultaneously for exhaust velocity $C_{3}$ and mean relative velocity angle $\beta_{\text {mean }}$, giving:

$$
\begin{aligned}
& U_{3 \text { mean }}=88.2 \mathrm{~m} / \mathrm{s} \\
& C_{3}=90.1 \mathrm{~m} / \mathrm{s} \\
& \beta_{\text {mean }}=45.6^{\circ}
\end{aligned}
$$

In summary, the major dimensions for our prototype turbine have been computed as follows:

Rotational speed: $N=22910 \mathrm{rad} / \mathrm{s}=218,775 \mathrm{rpm}$

Wheel diameter: $D_{2}=16.0 \mathrm{~mm}$

Eye tip diameter:

$D_{\text {tip }}=10.8 \mathrm{~mm}$

Eye hub diameter:

$D_{\text {hub }}=4.6 \mathrm{~mm}$

Number of blades:

$$
Z_{t r}=10
$$

Thickness of blades

$$
t_{t r}=0.6 \mathrm{~mm}
$$

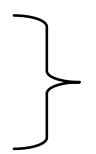

\section{Design of diffuser}

For the purpose of design, the diffuser can be seen as an assembly of three separate sections operating in series - a converging section or shroud, a short parallel section and finally the diverging section. The converging portion of the diffuser acts as a casing to the turbine. The straight portion of the diffuser helps in reducing the non-uniformity of flow, and in the diverging section, the pressure recovery takes place.

The geometrical specifications of the diffuser have chosen somewhat arbitrarily. Diameter of diffuser inlet is equal to diameter of the turbine inlet. Diameter of throat of diffuser is dependent on the shroud clearance. The recommended clearance is $2 \%$ of the exit 
radius, which is approximately $0.2 \mathrm{~mm}$ for wheel. The differential contraction between the wheel and the diffuser at low temperature usually acts to enhance this clearance. The profile of the convergent section has been obtained by offsetting the turbine tip profile by $0.2 \mathrm{~mm}$ radially. For diameter of diffuser exhaust, Balje (1981) suggested exit velocity of the diffuser should be maintained near about $20 \mathrm{~m} / \mathrm{s}$ with a half cone angle of $5.5^{\circ}$. Again by following Ino et al. (1992), the best suited diffusing angle $\left(=\tan ^{-1} \frac{\text { diameter }}{2 * \text { length }}\right)$ is 5 to 6 degree which minimizes the loss in pressure recovery and the aspect ratio $\left(=\frac{\text { length }}{\text { diameter }}\right)$ of 1.4 to 3.3 .

With the above recommended suggestions, the dimensions are selected as,
Diameter of diffuser inlet, $D_{i n D}$
$=\quad 16.5 \mathrm{~mm}$.
Diameter of throat of diffuser, $D_{t h D}$
$=\quad 11.0 \mathrm{~mm}$.
Diameter of diffuser exhaust, $D_{\text {exD }}$
Half cone angle
giving: Cross sectional area at throat, $A_{t h D}$
$=\quad 19.0 \mathrm{~mm}$.
$=\quad 5.0^{0}$
Discharge cross sectional area, $A_{t h D}$
$=\quad 95.0 \mathrm{~mm}^{2}$
Length of the diverging section $\mathrm{L}_{\mathrm{dD}}$
$=\quad 283.5 \mathrm{~mm}^{2}$
$=\quad 45.72 \mathrm{~mm}$

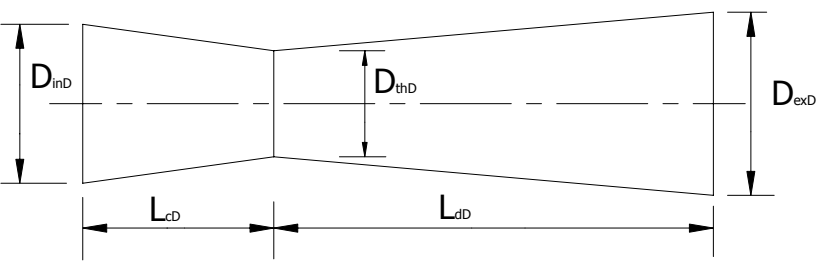

Figure 4: $\quad$ Diffuser nomenclatures

In order to assess the validity of the above dimensions of the diffuser, the Figure 5 is reproduced from Balje (1981). From the figure, in the divergent section, the length to throat radius ratio of 8.31 and exit area to throat area ratio 2.98 give a stable operation of recovery factor of 0.7 . This confirms the design of the diffuser.

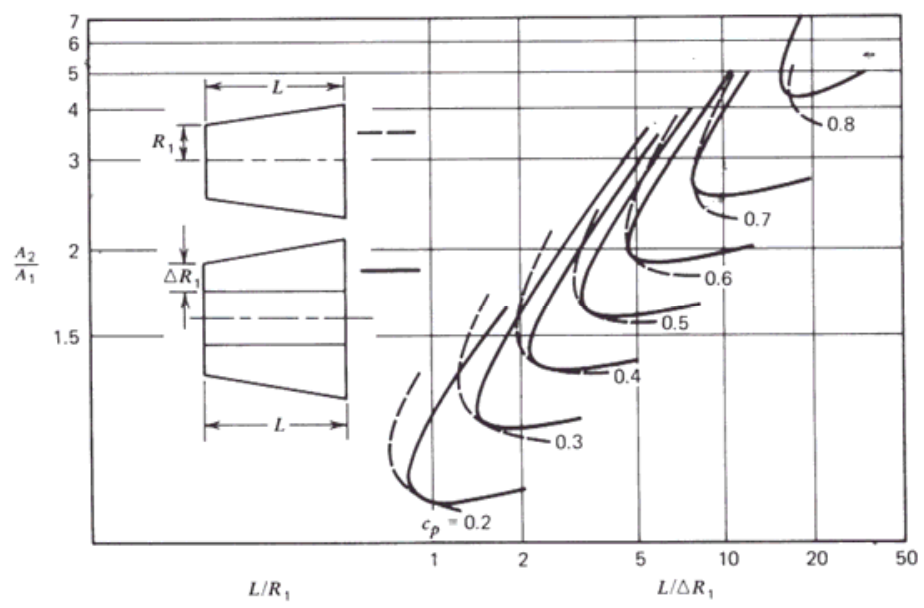

Figure 5: Performance diagram for diffusers (reproduced from Balje (1981))

\section{Thermodynamic state at wheel discharge (state 3)}

At the exit of the diffuser,

$$
Q_{e x}=3.97 \times 10^{-3} \mathrm{~m}^{3} / \mathrm{s} \text { and } \quad A_{e x}=0.2835 \times 10^{-3} \mathrm{~m}^{2}
$$

Therefore, exit velocity

$$
\mathrm{C}_{\mathrm{ex}}=\frac{Q_{e x}}{A_{e x}}=\frac{3.97 \times 10^{-3}}{0.2835 \times 10^{-3}}=14.0 \mathrm{~m} / \mathrm{s}
$$


This velocity is below $20 \mathrm{~m} / \mathrm{s}$ as suggested by Balje (1981).

Exit stagnation enthalpy:

$$
h_{0 e x}=h_{e x}+\frac{C_{e x}{ }^{2}}{2}=90.11+\frac{14^{2}}{2 \times 10^{3}}=90.20 \mathrm{~kJ} / \mathrm{kg}
$$

Exit stagnation pressure:

$$
\begin{aligned}
p_{0 e x} & =p+\frac{1}{2} \rho_{e x} C_{e x}^{2} \approx p \quad\left(\text { as velocity } C_{e x}\right. \text { is small) } \\
& =1.5+\frac{1}{2} \times 5.86 \times \frac{14^{2}}{10^{5}}=1.505 \text { bar } .
\end{aligned}
$$

Neglecting losses in the diffuser, the stagnation enthalpy at turbine exit,

$$
h_{03}=h_{0 e x}=90.20 \mathrm{~kJ} / \mathrm{kg} \text {, }
$$

From the stagnation enthalpy, $h_{03}$, and stagnation pressure $p_{0 e x}$, the entropy $s_{3}$ is estimated (Lemmon et al., 1995) as

$$
s_{3}=5.452 \mathrm{~kJ} / \mathrm{kg} \cdot \mathrm{K}
$$

and static enthalpy: $\quad h_{3}=h_{03}-\frac{C_{3}^{2}}{2}=90.20-\frac{90.1^{2}}{2 \times 1000}=86.15 \mathrm{~kJ} / \mathrm{kg}$

From static enthalpy, $h_{3}=86.15 \mathrm{~kJ} / \mathrm{kg}$ and $s_{3}=5.452 \mathrm{~kJ} / \mathrm{kg} . \mathrm{K}$, the density $\rho_{3}$ calculated (Lemmon et al., 1995) as $\rho_{3}=5.26$ $\mathrm{kg} / \mathrm{m}^{3}$.

The choice of $k_{1}=1.11$ is justified by comparing this density value with equations 6 . Therefore, the state point 3 is now fully described which can lead to the construction of velocity triangle of the turbine.

Tip circumferential velocity

$$
U_{3 t i p}=\frac{\omega D_{\text {tip }}}{2}=22910 \times \frac{10.8}{2 \times 1000}=123.7 \mathrm{~m} / \mathrm{s}
$$

Relative velocity at eye tip

$$
W_{3 t i p}=\sqrt{{U_{3 t i p}{ }^{2}+C_{3}^{2}}^{2}}=\sqrt{123.7^{2}+90.1^{2}}=153.0 \mathrm{~m} / \mathrm{s}
$$

Highest Mach Number

$$
\begin{aligned}
& \frac{W_{3 t i p}}{C_{s 3}}=\frac{153.0}{184.4}=0.83<1 \\
& \beta_{3 \text { tip }}=\tan ^{-1} \frac{C_{3}}{W_{3 t i p}}=\tan ^{-1} \frac{90.1}{123.7}=36.0^{\circ}
\end{aligned}
$$

Where $C_{s 3}$ is the velocity of sound for the corresponding state point as shown in Table 4 .

Similar figures for the eye hub at exit is estimated as

$$
U_{3 h u b}=52.7 \mathrm{~m} / \mathrm{s} \quad \mathrm{W}_{3 \mathrm{hub}}=104.4 \mathrm{~m} / \mathrm{s} \text {, and } \quad \beta_{3 \mathrm{hub}}=59.7^{\circ} \text {. }
$$


The velocity triangles at the hub, the tip and the mean radius of the eye have been shown in Figure 6. It may be noted that there are two components of velocity, $U_{2}$ and $W_{2}$ acting on the turbine wheel.

Table 4: Thermodynamic properties at state point 3

\begin{tabular}{|l|l|l|}
\hline & Stagnation value & Static value \\
\hline Velocity $(\mathrm{m} / \mathrm{s})$ & 0 & 90.1 \\
Pressure $(\mathrm{bar})$ & 1.505 & 1.29 \\
Enthalpy (kJ/kg) & 90.20 & 86.15 \\
Entropy $(\mathrm{kJ} / \mathrm{kg} . \mathrm{K})$ & 5.452 & 5.452 \\
Temperature (K) & 90.02 & 85.96 \\
Density $\left(\mathrm{kg} / \mathrm{m}^{3}\right)$ & 5.89 & 5.26 \\
Velocity of sound $(\mathrm{m} / \mathrm{s})$ & 188.87 & 184.4 \\
Viscosity (Pa.s) & $6.13 \times 10^{-6}$ & $5.90 \times 10^{-6}$ \\
\hline
\end{tabular}

\section{Thermodynamic state at wheel inlet (state 2)}

For computing the thermodynamic properties at wheel inlet (state 2), the efficiency of the expansion process till state 2 is assumed. Although in high-pressure ratio $(\sim 10)$ expansion, the nozzle efficiency $\eta_{n}$ is clearly described by Ino et al. (1992). Sixsmith (1971) has observed that the nozzle efficiency needs to be between 0.9 and 0.95. Following Kun and Sentz (1985), nozzle efficiency $\eta_{n}=0.93$ is assumed. Another important parameter is the ratio of inlet to exit meridional velocities $C_{m 2} / C_{m 3}$. Balje (1970) suggests values between 1.0 to 1.25 for this parameter. Following Kun and Sentz (1985), this ratio is assumed to be 1.0 , leading to

$$
\mathrm{C}_{\mathrm{m} 2}=\mathrm{C}_{\mathrm{m} 3}=\mathrm{C}_{3}=90.1 \mathrm{~m} / \mathrm{s} \text {. }
$$

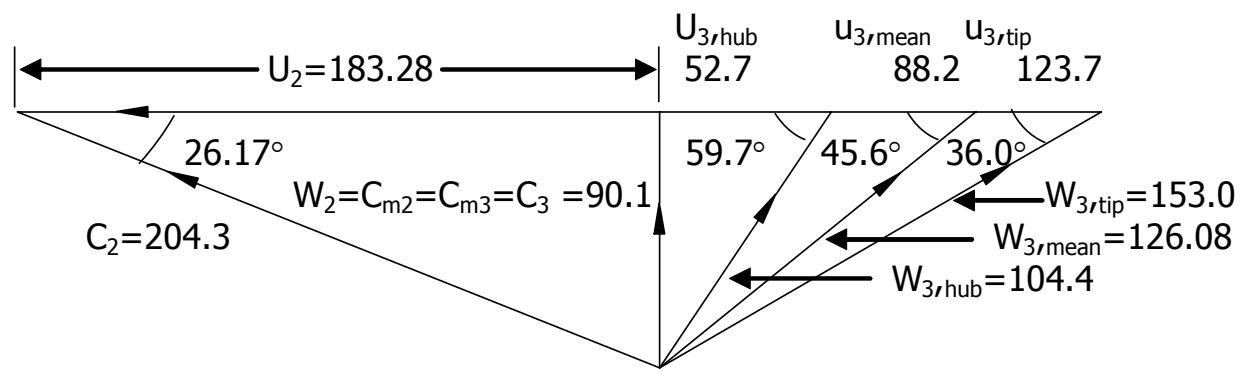

Figure 6: Velocity diagrams for expansion turbine (All velocities are in units of $\mathrm{m} / \mathrm{s}$ )

The third important assumption relates the gas angle at inlet of the rotor to the corresponding blade angle. Although a negative incidence between $10^{\circ}$ and $20^{\circ}$ has been recommended by authors (Whitfield et al., 1990; Rohlik et al., 1968), in our design radial blades have been adopted to ensure smooth incidence (Kun et al., 1985). Thus

$$
W_{2}=C_{m 2}=90.1 \mathrm{~m} / \mathrm{s}
$$

Then the absolute velocity at inlet:

$$
C_{2}=\sqrt{U_{2}^{2}+W_{2}^{2}}=\sqrt{183.28^{2}+90.1^{2}}=204.3 \mathrm{~m} / \mathrm{s}
$$

The incidence angle:

$$
\alpha_{2}=\tan ^{-1} \frac{\mathrm{W}_{2}}{\mathrm{U}_{2}}=\tan ^{-} \frac{90.1}{183.28}=26.17^{\circ}
$$

The efficiency of the nozzle along with the vaneless space is defined as 


$$
\eta_{n}=\frac{h_{\text {in }}-h_{2}}{h_{\text {in }}-h_{2 s}}
$$

Since $h_{01}=h_{0 \text { in }}=h_{\text {in }}=119.14 \mathrm{~kJ} / \mathrm{kgK}$ as input parameter, enthalpy at the exit of turbine wheel:

$$
h_{2}=h_{01}-\frac{C_{2}^{2}}{2}=119.14-\frac{204.3^{2}}{2 \times 1000}=98.27 \mathrm{~kJ} / \mathrm{kg}
$$

Thus $\quad h_{2 s}=h_{\text {in }}-\frac{h_{i n}-h_{2}}{\eta_{n}}=96.7 \mathrm{~kJ} / \mathrm{kg}$

The input parameter for entropy is expressed as:

$$
\mathrm{s}_{\text {in }}=\mathrm{s}_{1}=\mathrm{s}_{2 \mathrm{~s}}=5.339 \mathrm{~kJ} / \mathrm{kg} . \mathrm{K}
$$

Using property data (Lemmon et al., 1995), the corresponding pressure is calculated from $h_{2 s}$ and $s_{2 s}$ as:

$$
p_{2 s}=p_{2}=2.9 \mathrm{bar}
$$

From the values of $p_{2}$ and $h_{2}$, the other properties at the point 2 is calculated (Lemmon et al., 1995) as:

$$
T_{2}=99.65 \mathrm{~K}, \quad \rho_{2}=10.42 \mathrm{kj} / \mathrm{m}^{3} \text { and } s_{2}=5.352 \mathrm{kj} / \mathrm{kg} . \mathrm{K}
$$

Corresponding to these thermodynamic conditions:

velocity of sound $C_{s 2}=196.85 \mathrm{~m} / \mathrm{s}$,

specific heat $C_{p}=1.140 \mathrm{~kJ} / \mathrm{kgK}$ and

$$
\text { viscosity } \mu_{2}=6.88 \times 10^{-6} \text { pa.s }
$$

From continuity equation, the blade height at entrance to the wheel is computed as:

$$
b_{2}=\frac{\dot{m_{t r}}}{\left(\pi D_{2}-Z_{t r} t_{t r}\right) \rho_{2} C_{m 2}}=\frac{23.26 \times 10^{-3} \times 10^{6}}{(\pi \times 16-10 \times 0.6) \times 10.42 \times 90.1} \mathrm{~mm}=0.56 \mathrm{~mm}
$$

\section{Design of the nozzle}

An important forcing mechanism leading to fatigue of the wheel is the nozzle excitation frequency. As the wheel blades pass under the jets emanating from the stationary nozzles, there is periodic excitation of the wheel. This periodic excitation is proportional to the speed and the number of nozzle blades (Kun, 1987). The number of nozzle blades is normally dictated by mechanical design consideration, particularly to ensure that nozzle discharge does not excite natural frequency of the impeller (Kun and Sentz, 1985).

The purpose of the nozzle cascade is to assure that the flow should be incident on the wheel at correct angle to avoid incidence loss. Kun and Sentz (1985) selected the nozzle cascade height somewhat smaller than the tip width in order to leave some margin for expansion in the annular space around the wheel and to accommodate axial misalignment. This recommendation, although conforming to common design practice, is too restrictive in case of small turbines. Figure 7 shows the nozzle ring bringing out the major dimensions of the passages and the vanes. The design of the blading system offered no real problem as long as the pressure ratio across the turbine is not more than critical pressure ratio and as long as the temperature drop efficiency demanded does not exceed about 80\% (Von Der Nuell, 1952).

\section{Thermodynamic state at the throat and vaneless space}

The proposed system uses convergent type of nozzles giving subsonic flow at nozzle exit. Referring to Figure 7 the nozzle throat circle diameter is the outer boundary of the vaneless space while the wheel diameter is the inner circle. If $D_{t}$ is nozzle throat circle diameter and $C_{m t}$ the meridional component of the nozzle throat velocity, the mass balance equation yields,

$$
C_{m t}=\frac{\dot{m}}{\pi D_{t} b_{1} \rho_{t}}=\frac{23.26 \times 10^{-3} \times 10^{6}}{\pi \times D_{t} \times 0.5 \times \rho_{t}}
$$


Where $b_{1}$ is the height of the passage, assumed to be $0.5 \mathrm{~mm}$. The velocity at exit of the throat consists of two components, $C_{m t}$ and $C_{\theta t}$. The meridional component is perpendicular to the nozzle throat circle diameter, which determines the mass flow rate whereas the $C_{\theta t}$ other component is tangential to the throat.

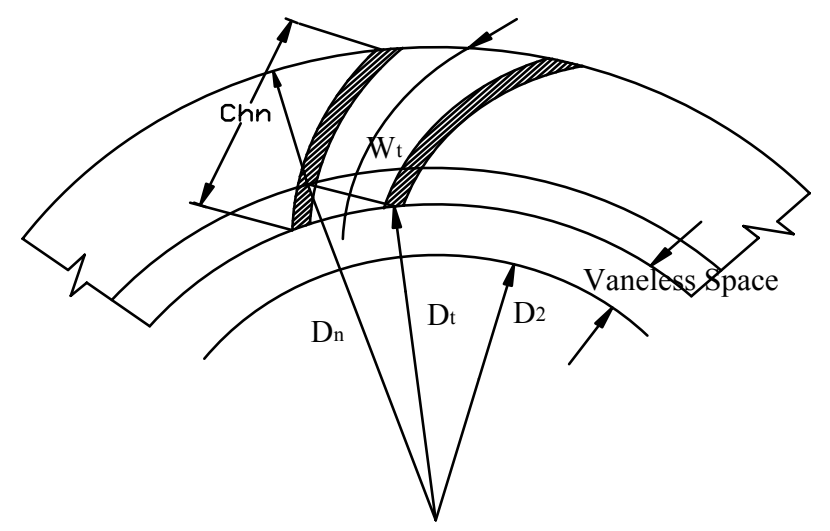

Figure 7: Major dimensions of the nozzle and nozzle vane.

Following Kun and Sentz (1985), $D_{t}=1.08 \times D_{2}=17.28 \mathrm{~mm}$, leading to

$$
C_{m t}=\frac{856.93}{\rho_{t}}
$$

Similar to the presence of two velocity components at the throat circle diameter, there are two velocity components at the entry of the turbine wheel as shown in Figure 3. From conservation of angular momentum in free vortex flow over the vaneless space,

$$
C_{\theta t}=\frac{U_{2} D_{2}}{D_{t}}=\frac{183.28}{1.08}=169.70 \mathrm{~m} / \mathrm{s}
$$

Thus, $\quad h_{t}=h_{2}+\frac{C_{2}{ }^{2}}{2}-\frac{C_{t}{ }^{2}}{2}$

Since $C_{t}$ consists of two velocity components perpendicular to each other,

$$
h_{t}=h_{2}+\frac{C_{2}{ }^{2}}{2}-\frac{C_{m t}{ }^{2}}{2}-\frac{C_{\theta t}{ }^{2}}{2}=119.14 \times 10^{3}-\frac{169.70^{2}}{2}-\frac{C_{m t}{ }^{2}}{2} \mathrm{~J} / \mathrm{kg}=104.74 \times 10^{3}-\frac{367.16 \times 10^{3}}{\rho_{t}^{2}}
$$

The relation between $h_{t}$ and $\rho_{t}$ given by equation (37) and the entropy conservation relation given below (Lemmon et al., 1995) uniquely determines enthalpy and density at that throat. Assuming isentropic expansion in the vaneless space,

$$
s_{t}=s_{1}=s_{2}=5.352 \mathrm{~kJ} / \mathrm{kgK}
$$

Solving the above equations,

$$
h_{t}=101.93 \mathrm{KJ} / \mathrm{kg} \text { and } \rho_{t}=11.45 \mathrm{~kg} / \mathrm{m}^{3}
$$

Using Ref. (Lemmon et al., 1995), the other properties at that throat are found to be

$$
p_{t}=3.30 \mathrm{bar} ; \quad T_{t}=103.5 \mathrm{~K} ; \quad \text { and } \quad C_{s t}=200.58 \mathrm{~m} / \mathrm{s}
$$

And the velocities are obtained from equations (35) and (36) as

$C_{t}=185.47 \mathrm{~m} / \mathrm{s} ; \quad C_{m t}=74.84 \mathrm{~m} / \mathrm{s} ;$ and $C_{\theta t}=169.7 \mathrm{~m} / \mathrm{s}$, and

Mach number: $\quad M_{t}=\frac{C_{t}}{C_{s t}}=0.92$

This leads to subsonic operation with no loss energy on account of aerodynamic shocks. 


\section{Sizing of the nozzle vanes}

To compute the dimensions of the throat, Kun \& Sentz (1985) used the conservation of momentum \& continuity of flow to get the correct throat angle for finite trailing edge thickness. Aerodynamically, it is desirable to make the trailing edge as thin as mechanical design consideration will allow.

Using the Continuity Equation and the density at the throat, the throat width $\mathrm{w}_{\mathrm{t}}$ and the throat angle $\alpha_{t}$ are calculated as follows.

For $\dot{m}_{t r}=\dot{m}=23.26 \times 10^{-3} \mathrm{~kg} / \mathrm{s}$ and $b_{1}=b_{t}$

$$
\begin{aligned}
& W_{t}=\frac{\dot{m}_{t r}}{Z_{n} b_{t} \rho_{t} C_{t}}=\frac{23.26 \times 10^{-3} \times 10^{6}}{15 \times 0.5 \times 11.45 \times 185.47}=1.46 \mathrm{~mm} \\
& \alpha_{t}=\tan ^{-1}\left(\frac{C_{m t}}{C_{\theta t}}\right)=23.8^{o}
\end{aligned}
$$

It may be noted that throat inlet angle is different from the turbine blade inlet angle and the discrepancy is due to the drifting of fluid in the vaneless space.

The initial guess value of $D_{t}$ is checked from the conservation of angular momentum over the vaneless space,

$$
D_{t}=\frac{U_{2} D_{2}}{C_{\theta t}}=17.28 \mathrm{~mm}
$$

which matches to the initial value of $17.28 \mathrm{~mm}$.

The blade pitch length, $p_{n}$ is estimated as,

$$
p_{n}=\pi D_{t} / Z_{n}=3.62 \mathrm{~mm}
$$

$\alpha_{t}$ is the angle between the perpendicular to the throat width $w_{t}$ and the tangent to the throat circle diameter. From Figure 7 , the diameter of the cascade discharge (the inner diameter of the nozzle ring) is calculated as,

$$
D_{n}=\sqrt{D_{t}^{2}+w_{t}^{2}-2 w_{t} D_{t} \operatorname{Cos} \alpha_{t}}=26.82 \mathrm{~mm}
$$

where $\alpha_{t}$ is angle between $D_{t}$ and $w_{t}$.

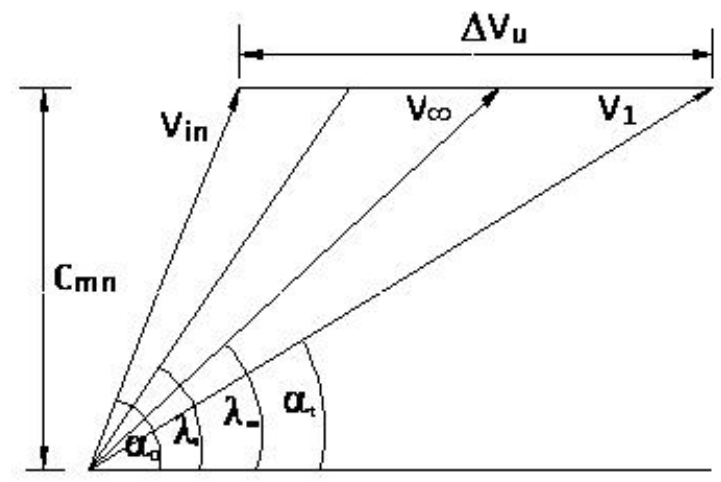

Figure 8: Cascade notation

In cascade theory, blade loading and cascade solidity are defined as:

$$
\delta u=\frac{\Delta V_{u}}{C_{m n}}=\cot \alpha_{t}-\cot \alpha_{0} \quad \sigma_{n}=\frac{C h_{n}}{S}
$$

From cascade notation, $\cot \alpha_{t}=\cot \lambda_{\infty}-\frac{\delta u}{2}$ and $\cot \alpha_{0}=\cot \lambda_{\infty}+\frac{\delta u}{2}$ 
The separation limit, in an approximate way, is expressed by a minimum required solidity. Its value is found from the aerodynamic load coefficient $\psi_{z}$ defined as the ratio of actual tangential force to ideal tangential force, also known as Zweifel number. The optimum value for the aerodynamic load coefficient is about 0.9. Thus the chord length of nozzle can be found from the equation of solidity and expressed as

$$
C h_{n}=\frac{2 s\left(\cot \alpha_{t}-\cot \alpha_{0}\right) \sin ^{2} \alpha_{t}}{\psi_{z} \sin \lambda_{s}}=\frac{2 \delta u \times S}{\psi_{z}\left[1+\left(\cot \lambda_{\infty}+\frac{\delta u}{2}\right)^{2}\right] \sin \lambda_{s}}
$$

Where

$\mathrm{S}=$ tangential vane spacing $=\pi D_{n} / Z_{n}=4.95 \mathrm{~mm}$.

$\lambda_{\infty}=$ cascade angle or mean vector angle $=\cot ^{-1}\left(\frac{\cot \alpha_{t}+\cot \alpha_{0}}{2}\right)$

$\lambda_{s}=$ stagger angle $=\lambda_{\infty}+\alpha_{m}$

Following Balje (1981), $\alpha_{0}$ is taken as $78^{\circ}$ and also gives $\alpha_{m}$ as a function of $\Delta \lambda=\left(\alpha_{0}-\alpha_{t}\right)$ for various values of $\lambda_{\infty}$, yields $\alpha_{m}=-4^{\circ}$, leading to: $\delta_{u}=2.75, \lambda_{\infty}=34.2^{\circ}, \lambda_{s}=28.2^{\circ}$ and $C h_{n}=6.58 \mathrm{~mm}$.

\section{Conclusions}

A numerical model of the cryogenic turbine wheel has been developed covering hub and tip to study the design and operating parameters on the size of the blade. In addition, the flow chart will play a significant role to find state properties and dimension of cryogenic turboexpander. By using this method the designer is able to get a better feel for the turbine wheel during the design process, he spends less time on mundane data preparation, and he has more freedom to make full use of this creativity to design a better machine. Based on this design, development and experimental work is needed to get the better design and characterize the operation of the devices at higher speeds, including stability, load capacity and heat dissipation. The paper presents an updated literature review on almost all aspects of design of cryogenic turbine, and may serve as a ready reference for future work.

\section{Nomenclature}

\begin{tabular}{|ll|ll|}
\hline $\mathrm{b}$ & blade height $(\mathrm{mm})$ & \multicolumn{2}{|l|}{ Greek symbols } \\
$\mathrm{C}$ & absolute velocity $(\mathrm{m} / \mathrm{s})$ & $\omega$ & rotational speed $(\mathrm{rad} / \mathrm{s})$ \\
$\mathrm{C}_{\mathrm{n}}$ & chord length of nozzle $(\mathrm{mm})$ & $\lambda$ & ratio of hub diameter to tip diameter \\
$\mathrm{d}_{\mathrm{s}}$ & specific diameter & $\varepsilon$ & ratio of tip diameter to turbine wheel diameter \\
$\mathrm{D}$ & diameter $(\mathrm{mm})$ & $\eta$ & isentropic efficiency (dimensionless) \\
$\mathrm{h}$ & enthalpy $(\mathrm{J} / \mathrm{kg})$ & $\beta$ & relative velocity angle \\
$\mathrm{M}$ & mach number & $\rho$ & density of gas $(\mathrm{m} 3 / \mathrm{kg})$ \\
$\mathrm{m}$ & & Subscripts \\
$\mathrm{m}$ & mass flow rate $(\mathrm{Kg} / \mathrm{s})$ & 0 & stagnation condition \\
$\mathrm{n}_{\mathrm{s}}$ & specific speed & 1 & inlet to nozzle \\
$\mathrm{N}$ & rotational speed $(\mathrm{rev} / \mathrm{min})$ & 2 & inlet to turbine wheel \\
$\mathrm{p}$ & pressure $($ bar $)$ & 3 & inlet to the diffuser $(\mathrm{exit}$ to wheel) \\
$\mathrm{P}$ & power produced $(\mathrm{Kw})$ & $\mathrm{ex}$ & discharge from diffuser \\
$\mathrm{Q}$ & volumetric flow rate $(\mathrm{m} 3 / \mathrm{s})$ & $\mathrm{hub}$ & hub of turbine wheel \\
$\mathrm{T}$ & temperature $(\mathrm{K})$ & tip & tip of turbine wheel \\
$\mathrm{t}$ & thickness of blades $(\mathrm{mm})$ & $\mathrm{m}$ & meridional component \\
$\mathrm{U}$ & circumferential velocity $(\mathrm{m} / \mathrm{s})$ & $\mathrm{s}$ & isentropic condition \\
$\mathrm{W}$ & relative velocity $(\mathrm{m} / \mathrm{s})$ & $\mathrm{tr}$ & turbine wheel \\
$\mathrm{W}$ & width of flow passage $(\mathrm{mm})$ & $\mathrm{n}$ & nozzle \\
$\mathrm{z}$ & number of blades & $\mathrm{t}$ & throat \\
\hline
\end{tabular}




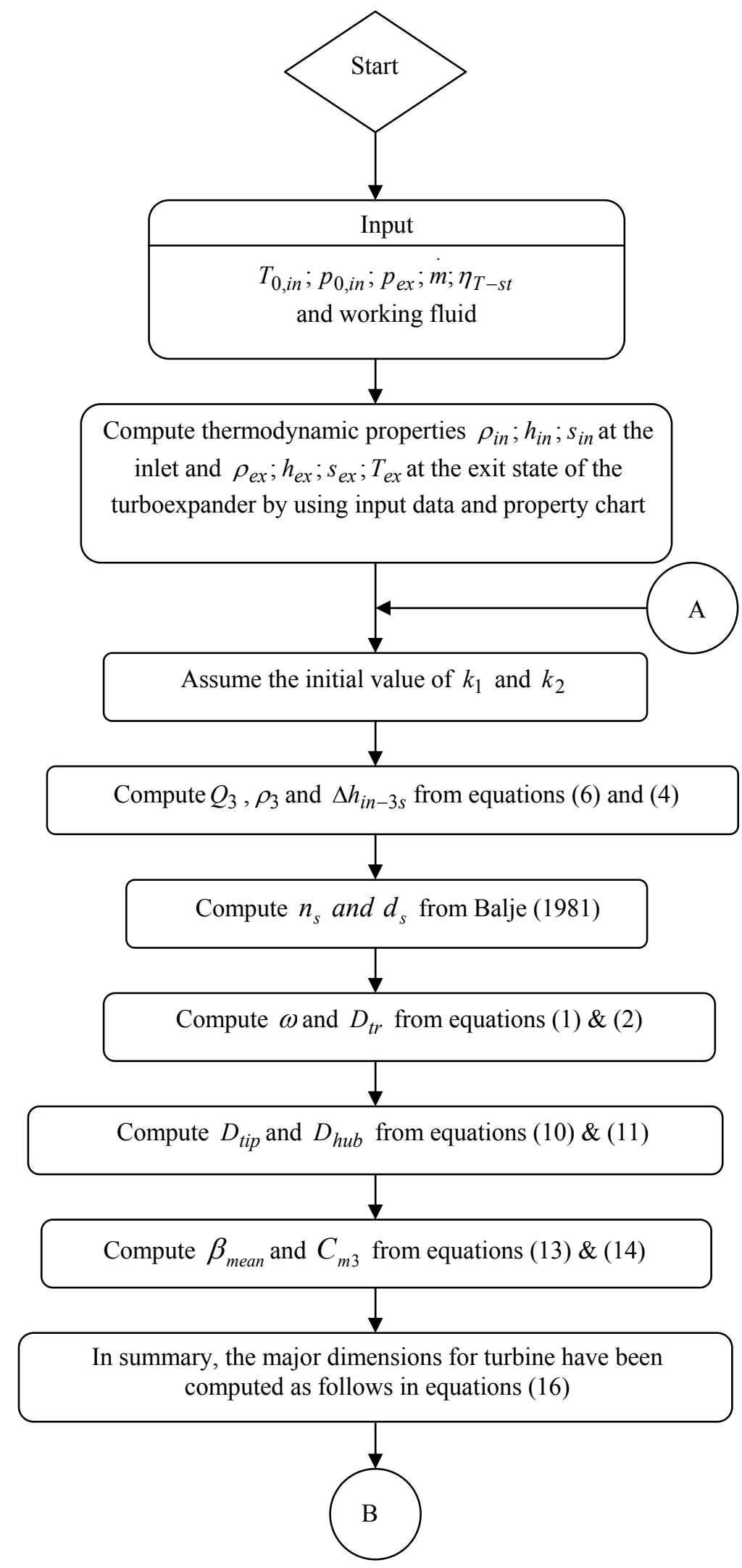




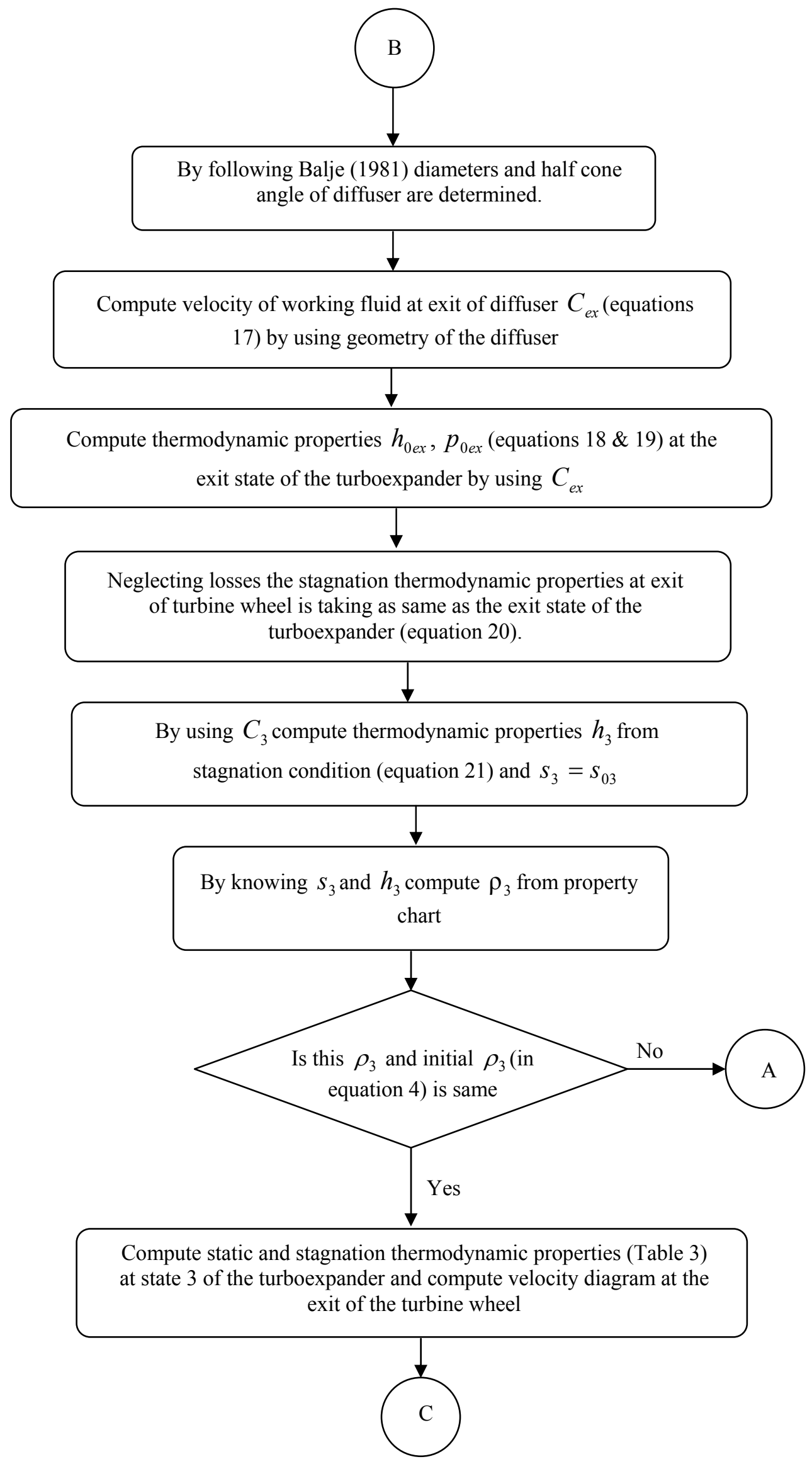




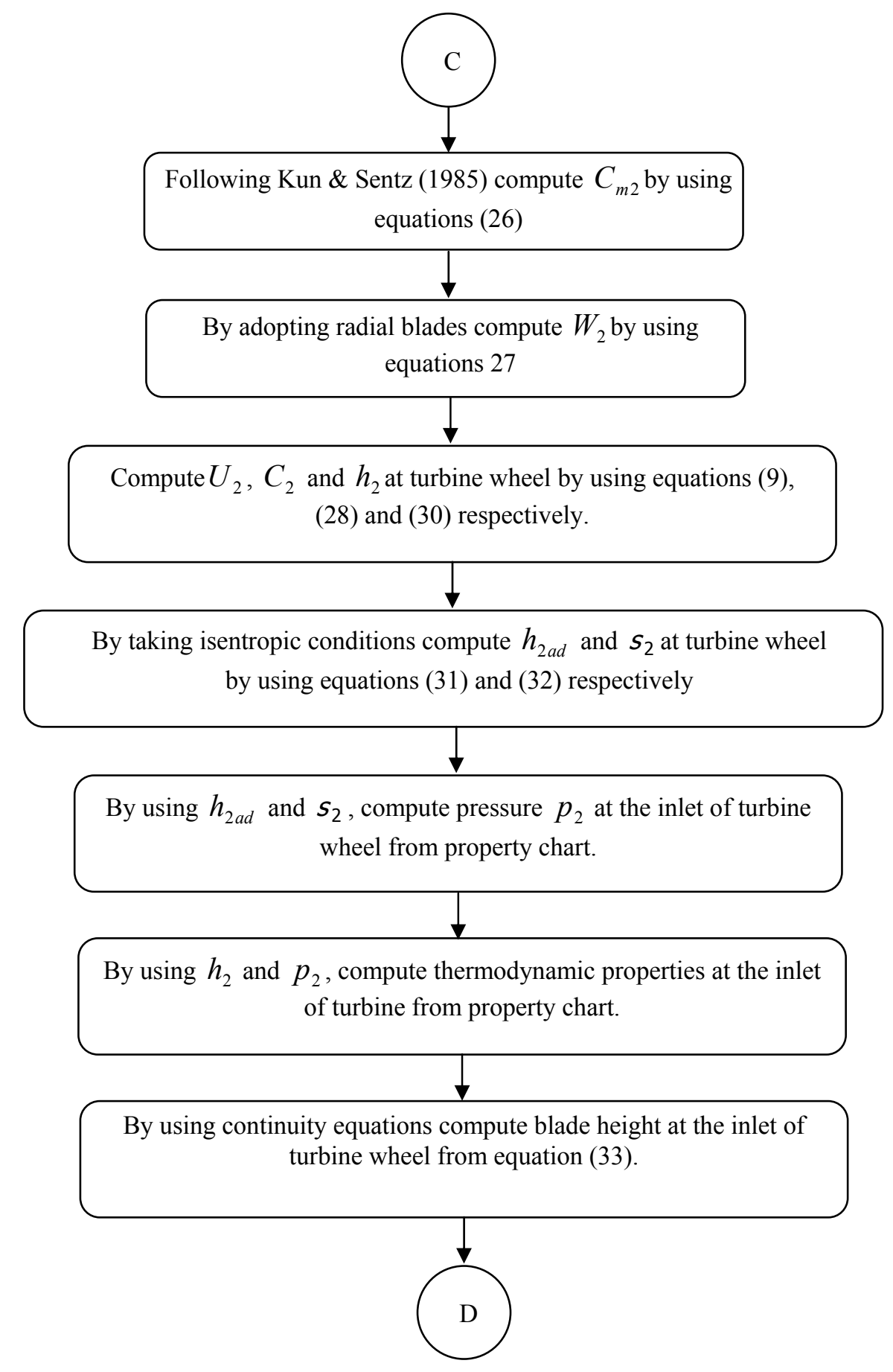




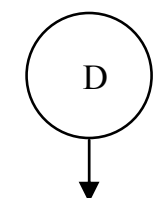

Following Kun \& Sentz (1985), the number of nozzle blades is 15 and thickness is $0.5 \mathrm{~mm}$ has been taken.

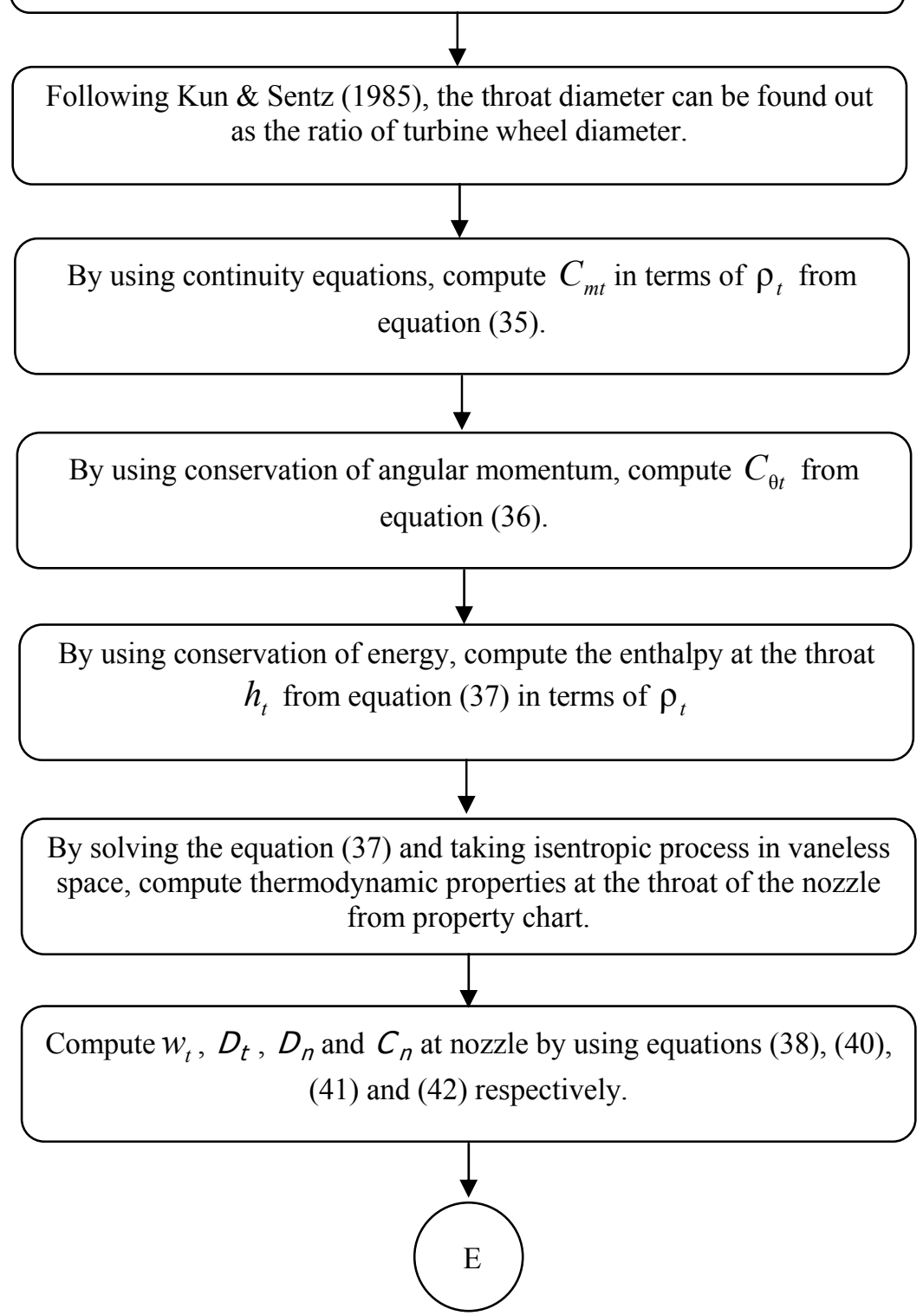

Figure 9: Flow chart for calculation of state properties and dimension of cryogenic turboexpander

\section{References}

Abidat M., Hamidou M.K., Hachemi M. and Hamel M., 2006. Design and flow analysis of radial and mixed flow turbine volutes, European Conference on Computational Fluid Dynamics, ECCOMAS CFD Egmond Aan Zee, The Netherlands.

Baines, N. 2002. Radial and mixed flow turbine options for high boost turbochargers, 7th international conference on Turbochargers and Turbocharging, London, pp. 35-44.

Balje, O. E. 1981. Turbomachines, John Wiley and Sons, London.

Balje, O. E. 1970. Loss and flow path studies on centrifugal compressors, Part-II Trans ASME J Eng Power, No-70, pp. 275-299.

Beasley, S. A. and Halford, P. 1965. Development of a high purity nitrogen plant using expansion turbine with gas bearing, Advances in Cryogenic Engineering, V10B, pp. 27-39. 
Bruce, G. J. 1998. Computer-aided turbomachinery design system, I Mech E Conference on Turbochargers, I Mech E Publications, London, C554/026/98, pp. 3-22.

Denton, J. D. 1996. The turboexpander - a design, make and test student project ASME-96-GT- 191.

Descombes G., Maroteaux F., Moreno N., Jullien J. 2003. Analysis of energy conversion within a radial turbine stage, Int. J. Thermodynamics, Vol.6, No.1, pp.41-48.

Dixon, S. L. 1978. Fluid Mechanics and Thermodynamics of Turbomachinery (3rd ed) Pergamon Press, London.

Ghosh, S. K., Seshaiah, N., Sahoo. R. K., Sarangi. S. K. 2005. Design of turboexpander for cryogenic applications, Indian J. Cryogenics, Special Issue Vol-2, pp. 75-81.

Ghosh, S. K., Sahoo. R. K., Sarangi. S. K. 2009. A computational approach to the design of a cryogenic turbine blade profile, International Journal of Engineering, Science and Technology, Vol. 1, No. 1, pp. 43-60.

Ghosh, P. 2002. Analytical and Experimental Studies on Cryogenic Turboexpanders Ph.D dissertation, IIT Kharagpur

Hasselgruber, H. 1958, Stromungsgerechte gestaltung der laufrader von radialkompressoren mit axialem laufradeintrict Konstruction, Vol. 10, No. 1, pp. 22 (in German)

Ino, N., Machida, A. and Ttsugawa, K. 1992. Development of high expansion ratio He turboexpander, Advances in Cryogenic Engineering, V37B, pp. 835-844.

Jekat, W. K. 1957. An impulse type expansion turbine, Advances in Cryogenic Engineering, V2, 250-260.

Jadeja, H. T., Mitter, A. and Chakrabarty, H. D. 1985. Turboexpander application for cryoprocessing of nitrogen and related gases Proceedings of inconcryo, 85 Indian Cryogenic Council, Tata McGraw, pp. 85-101.

Kun, L .C. and Sentz, R. N. 1985. High efficiency expansion turbines in air separation and liquefaction plants, International Conference on Production and Purification of Coal Gas \& Separation of Air, Beijing, China, pp. 1-21

Kun, L. C. 1987. Expansion turbines and refrigeration for gas separation and liquefaction, Advances in Cryogenic Engineering, V33, pp. 963-973.

Lemmon, E. W., Jacobsen, R. T., Penoncello, S. G. and Beyerlein, S. W., 1995. ALLPROPS 4.2 - Computer programs for calculating thermodynamic properties of fluids of engineering interest, Centre for Applied Thermodynamic Studies, University of Idaho

Rohlik, Harold E. 1968. Analytical determination of radial inflow turbine geometry for maximum efficiency NASA TN D-4384.

Sixsmith, H. 1971. Miniature expansion turbines, C A Bailey (Ed), Advanced Cryogenics Plenum Press, London pp. 225-243.

Sixsmith, H., Valenjuela, J. and Swift, W. L. 1988, Small Turbo-Brayton cryocoolers Advances in Cryogenic Engineering, V34, $827-836$

Stewart, W.L. and Glassman, A. J. 1973. Turbine Design and Application, NASA SP-290, London, Vol. 2, pp. 1-25.

Von Der Nuell, W. T. 1952. Single-stage radial turbine for gaseous substances with high rotative and low specific speed, Trans ASME, V74, pp. 499-515.

Whitfield, A. and Baines, N. C. 1990. Design of Radial Turbomachines, Longman Scientific \& Technical, NewYork.

Yang, K. J., He, H. B., Ke, G. and Li, G. Y. 1990. Application and test of miniature gas bearing turbines, Advances in Cryogenic Engineering, V35, pp. 997-1003.

\section{Biographical notes}

Dr. Subrata Kumar Ghosh is Senior Lecturer in the Department of Mechanical Engineering \& Mining Machinery Engineering at ISM, Dhanbad, India. Before joining at ISM He was Lecturer at BIT, Mesra. His research has focused on Thermal Engineering. He is the author and coauthor of over 8 articles, which have appeared in journals such as Applied Thermal Engineering, Indian Journal of Cryogenics, and several seminars.

Received December 2009

Accepted January 2010

Final acceptance in revised form March 2010 